\title{
Adaptive Neural Network-Based Control of a Hybrid AC/DC Microgrid
}

\author{
N. Chettibi, A. Mellit, G. Sulligoi, IEEE Senior Member, and A. Massi Pavan, IEEE Member
}

\begin{abstract}
In this paper, the behavior of a grid-connected hybrid AC/DC Microgrid has been investigated. Different Renewable Energy Sources - photovoltaics modules and a wind turbine generator - have been considered together with a Solid Oxide Fuel Cell and a Battery Energy Storage System. The main contribute of this work is the design and the validation of an innovative online-trained artificial neural network based control system for a hybrid microgrid. Adaptive Neural Networks are used to track the Maximum Power Point of renewable energy generators and to control the power exchanged between the Front-End Converter and the electrical grid. Moreover, a fuzzy logic based Power Management System is proposed in order to minimize the energy purchased from the electrical grid. The operation of the hybrid microgrid has been tested in the Matlab/Simulink environment under different operating conditions. The obtained results demonstrate the effectiveness, the high robustness and the self-adaptation ability of the proposed control system.
\end{abstract}

Index Terms - Adaptive interaction, fuel cells, microgrid, neural networks, photovoltaics, predictive control, wind energy, battery energy storage system.

\section{NOMENCLATURE}

$\mathrm{AC}$

ADALINE

AI

BESS

BP

CL

CPL

DC

DPC

DPCM

ENN

FEC

FFNN

FL

HL

IncCond

IL

LMS

MG

MPP

MPPT

$\mathrm{NN}$

OL

PI

PMS

PMSG
Alternate Current

ADAptive LInear NEuron

Adaptive Interaction

Battery Energy Storage System

Back-Propagation

Context Layer

Constant Power Load

Direct Current

Direct Power Control

Deadbeat Predictive Control Method

Elman Neural Network

Front-End Converter

Feed Forward Neural Network

Fuzzy Logic

Hidden Layer

Incremental Conductance

Input Layer

Least Mean Squares

Micro-Grid

Maximum Power Point

Maximum Power Point Tracking

Neural Network

Output Layer

Proportional Integral

Power Management System

Permanent Magnetic Synchronous Generator
PV

RBFN

RES

SOFC

SN-RBFN

SMC

SOC

SVM

TS-AF

VF

WT

WEGS
Photovoltaic

Radial Basis Function Network

Renewable Energy Sources

Solid Oxide Fuel Cell

Single Neuron Radial Basis Function Network

Sliding Mode Control

State Of Charge

Space Vector Modulator

Tangent-Sigmoid Activation Function

Virtual Flux

Wind Turbine

Wind Energy Generation System

\section{INTRODUCTION}

$\mathrm{N}$ OWADAYS, the wide diffusion of distributed RES presents a new scenario for the regulation of distribution networks and the availability of new technologies for storage systems encourages their use in power systems [1]. In general, a hybrid AC/DC MG integrates different Distributed Generators (e.g. solar power sources, wind power generators, cogenerators, etc.), a energy storage system and a number of AC and DC loads. A FEC can interface the MG with the electric grid and can operate either in a grid-connected or islanded mode. The use of a PMS is crucial to optimize the power flow through the different components of the MG and the exchange of energy with the electric grid. Moreover, since the power produced by RESs depends on the climatic conditions, MPPT algorithms are needed in order to harvest the maximum available energy. The intermittent nature of RESs with the time-varying loads demand make the use of advanced control structures fundamental in order to make the operation of the MG reliable, economic, and secure under different operating conditions. The MG must also guarantee a high quality power supply to both local loads and electrical grid.

Many works have focused on hybrid microgrids and have proposed a number of control schemes for different mode of operations [2]-[8]. A multiagent-based energy management system to optimizes the economic operation of a $\mathrm{MG}$ is presented in [2]. A reactive power sharing algorithm in hierarchical droop control is developed in [3]. A novel coordinated voltage control scheme with islanding capability for a MG is proposed in [4]. For highly nonlinear and complex AC/DC MGs, control schemes based on artificial intelligence techniques such as Fuzzy Logic (FL), Neural Network (NN), and evolutionary algorithms are gaining widespread interest. Intelligent controllers are very promising because they can 
adapt to uncertainties and they can be used also when the model of the system to be controlled is not available. Recently, the NNs with the learning capability are widely applied for the control of complex power systems. In [9], a back-propagation $\mathrm{NN}$ is applied for the real-time estimation of the wind speed. A novel discrete-time NN controller for the control of DC distribution system is designed in [10]. In [11], a RBFN and an improved ENN are proposed as MPPT controllers for different types of RES. A RBFN with an ENN have been also analyzed in [12] for the wind speed prediction in a wind farm.

The different NNs based techniques proposed in the literature can be classified, according to the training algorithm, into two categories [13]: offline and online trained NN. Offline learning of a neuro-controller is usually accomplished using a training dataset coming from the system model or from experimental data. When the controlled system is too complex to be modeled and/or experimental datasets are not available, it is more adequate to use online trained NNs that respond dynamically to the system uncertainties resulting from nonlinearities, parameters changing and exterior perturbations.

In this paper, a grid-connected hybrid MG which consist of a PV source, a WT generator, a SOFC, a BESS and two equivalent DC and AC loads is studied. A PMS based on FL is proposed to supervise the power flow in the MG. Onlinetrained NNs based MPPT for the RESs in addition to ADALINE based linear controllers for both SOFC stack and BESS are introduced. Moreover, a simplified deadbeat based predictive control scheme is applied for the WEGS. Further, a VF-DPC strategy for the bidirectional FEC is adopted. A FFNN is proposed for the regulation of the DC-bus voltage. Two ENNs based controllers are adopted to ensure the control of the bidirectional flow of the active power as well as the compensation of the AC load reactive power. An AI based algorithm is applied for the online weights adaptation of the proposed FFNN and ENNs. The investigated MG is simulated in the Matlab/Simulink environment. Then, the effectiveness of the proposed controllers is verified for different test cases.

The paper is organized as follows: the next Section in on the configuration and the modeling of the MG, Section III deals with the control scheme, the simulation results are given in Section IV, and Section V is on Conclusions and Perspectives.

\section{SYSTEM CONFIGURATION AND MODELING}

As shown in Fig.1, the investigated MG is connected to the electric grid though a FEC, while the DC-Bus is fed by four energy sources: a $21 \mathrm{kWp}$ PV generator, a $10 \mathrm{~kW}$ WEGS, a $10 \mathrm{~kW}$ SOFC, and a 20Ah Lithium-Ion BESS. A bidirectional buck-boost converter interfaces the BESS with the DC link. Whereas, boost converters are used for coupling the PV source and SOFC with the DC-bus. A filter capacitor $\mathrm{C}_{\mathrm{dc}}$ is connected to the DC-bus to minimise the DC voltage ripples. Moreover, the MG includes also AC and DC loads. The circuit model of the converters used in the MG is shown in Fig.2.

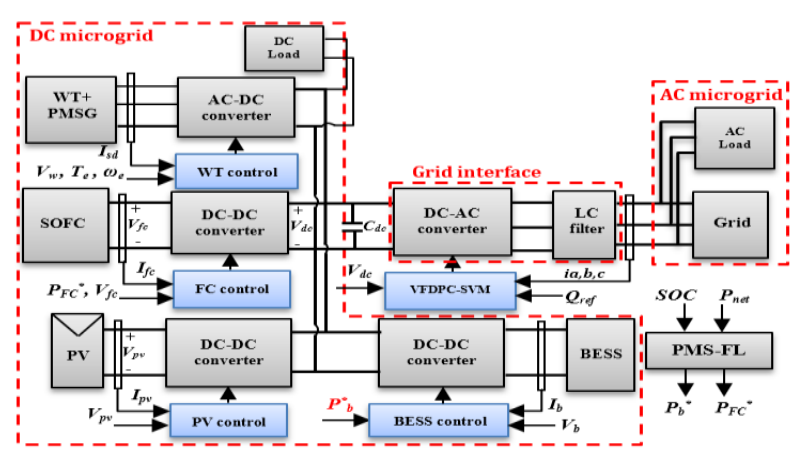

Fig. 1. Hybrid Microgrid configuration.

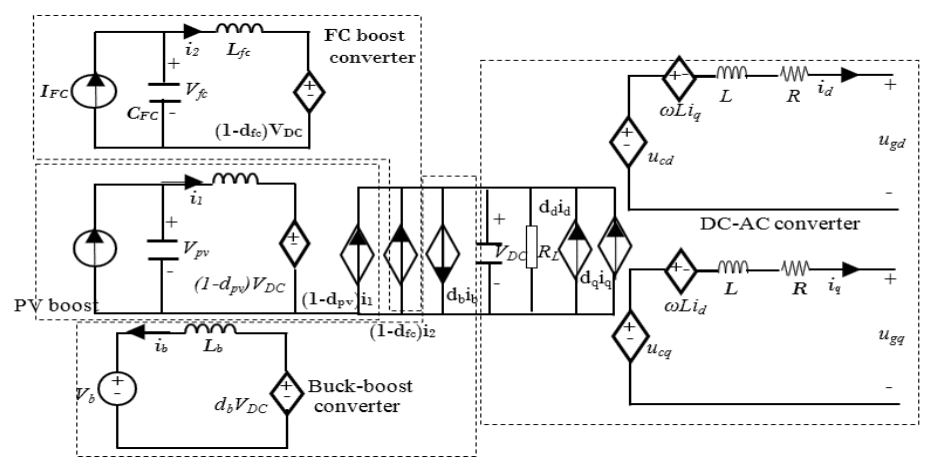

Fig. 2. Circuit model of the considered converters.

\section{A. Modeling the PV generator}

The equivalent circuit used to model a PV module is shown in Fig. 3 and is represented by the following equation [14]:

$$
I_{P V}=n_{p} I_{P H}-n_{p} I_{S}\left[\exp \left(\frac{q}{A K T}\right)\left(\frac{V_{P V}}{n_{s}}+I_{P V} R_{S}\right)-1\right]
$$

Where $I_{P V}$ and $V_{\mathrm{PV}}$ are the PV module's output current and voltage, $R_{S}$ is the series resistance, $I_{\mathrm{PH}}$ is the photocurrent, $I_{S}$ is the saturation current, $q$ is the electron charge, $K$ is the Boltzman constant, $A$ is the diode ideality factor, $T$ is the temperature, while $n_{P}$ and $n_{S}$ are the numbers of series and parallel-connected solar cells.

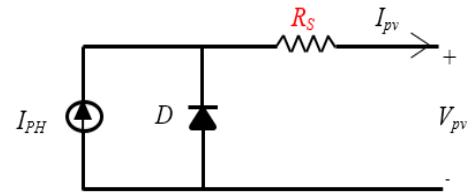

Fig. 3. Single diode equivalent circuit of PV module.

\section{B. Modeling the Wind Energy Generation System}

The WEGS consists of a WT coupled to a PMSG, where an AC-DC Rectifier is used for the interfacing with the DC-bus. The mathematical model of the PMSG implemented in the synchronous rotating frame $d q$ is given as $[15,16]$ :

$$
\left\{\begin{array}{c}
V_{s d}=-R_{s} I_{s d}-L_{s d} \frac{d I_{s d}}{d t}+L_{s q} \omega_{e} I_{s q} \\
V_{s q}=-R_{s} I_{s q}-L_{s q} \frac{d I_{s q}}{d t}-L_{s d} \omega_{e} I_{s d}+\omega_{e} \phi
\end{array}\right.
$$

Where $V_{s d}, V_{s q}, I_{s d}$ and $I_{s q}$ are the $d$ and $q$-axis components of the stator voltages and currents; $L_{s d}$ and $L_{s d}$ are the d and qaxis inductance, $\omega_{e}$ is the generator speed defined as [15]: $\omega_{e}=p . \omega_{t}$ such that $p$ is the number of pole pairs and $\omega_{t}$ is the angular velocity of WT, $\phi$ is the permanent magnet flux, and $R s$ is the stator resistance. The electromagnetic torque $T_{e}$ developed by the generator can be written as [16]: 


$$
T_{e}=\frac{3}{2} p\left(\left(L_{s d}-L_{s q}\right) I_{s q} I_{s d}+\phi I_{s q}\right)
$$

Considering that for nonsalient PMSG $L_{s d}=L_{s q}=L_{s}$, Eq.3 can be rewritten as:

$$
T_{e}=\frac{3}{2} p I_{s q} \phi
$$

Since the magnetic flux is constant, the electromagnetic torque and the q-axis stator current component $I_{s q}$ are directly proportional. Whereas, the reactive power may be controlled depending on the d-axis current component $I_{s d}$. The motion equation is given by [15]:

$$
J \frac{d \omega_{m}}{d t}=T_{t}-T_{e}-F \omega_{m}
$$

Where $F$ is the viscous friction factor, $J$ is the moment of inertia. The aerodynamic torque of WT is defined as the ratio between the aerodynamic power $P_{t}$ and the WT angular velocity:

$$
T_{t}=P_{t} / \omega_{t}=0.5 \pi \rho R^{2} C_{P} V_{W}^{3} / \omega_{t}
$$

Where $\rho, V_{W}, R, C_{P}$ are the air density, the wind speed, the radius of turbine blade and the power coefficient, respectively.

\section{Modeling the Solid Oxide Fuel Cell}

The dynamic model adopted for the SOFC $[17,18]$ is based on the relationship between the FC output voltage $V_{f c}$ and the partial pressures of hydrogen, oxygen, and water $P_{\mathrm{H} 2}, P_{\mathrm{O} 2}$, $P_{H 2 O}$, respectively. The SOFC terminal voltage $V_{f c}$ is determined using the Nernst's equation and Ohm's law as $[17,18]$ :

$$
V_{f c}=N_{0}\left(E_{0}+\frac{R T}{2 F}\left(\ln \left(\frac{P_{H_{2}} P_{O_{2}}^{0.5}}{P_{\mathrm{H}_{2} \mathrm{O}}}\right)\right)\right)-r I_{f c}
$$

Where $N_{0}$ is the number of series connected cells, $E_{0}$ is the free reaction voltage, $\mathrm{R}$ is the universal gas constant, $\mathrm{T}$ is the temperature, $\mathrm{F}$ is the Faraday's constant, $I_{f c}$ is the FC output current, and $r$ is the ohmic resistance.

\section{Modeling the Battery Energy Storage System}

The Matlab/Simulink module used for the BESS simulation consists of a controlled voltage source series-connected with an internal resistance [19]. The battery output voltage and the State Of Charge (SOC) are calculated as follows:

$$
\begin{gathered}
V_{b}=E_{0}-R_{\text {in }} I_{b}-K \frac{Q}{Q-\int_{0}^{t} I_{b}(t) d t}+A \exp \left(-B \int_{0}^{t} I_{b} d t\right)(8) \\
S O C=100\left(1-\frac{\int_{0}^{t} I_{b} d t}{Q}\right)
\end{gathered}
$$

Where $V_{b}$ and $I_{b}$ are the BESS terminal voltage and current, $E_{0}$ is the BESS no-load voltage, $R_{i n}$ is the internal resistance, $K$ is the polarization voltage, $Q$ is the BESS capacity, $A$ is the exponential zone amplitude, and $B$ is the inverse exponential zone time constant. In this paper, a 20 Ah Lithium-Ion battery bank is used.

\section{CONTROL STRUCURE OF THE HYBRID MICROGRID}

The main tasks of the control system of a hybrid MG are: to minimize the amount of power purchased from the electric grid, to make the RESs based generators operate at their MPPs and to ensure a high-quality power supply to local loads and to electric grid. Being motivated by the benefits of learning ability, robustness against uncertainties and adaptability, a number of intelligent NN controllers have been designed and used instead of the conventional controllers, in order to satisfy the above requirements.

\section{A. MPPT control of PV generator}

The PV source exhibits a nonlinear behavior depending upon the variable operating conditions, and the maximum output power is generated at an unique operating point. Several MPPT algorithms heva been proposed in the litherature to extract the maximum energy from PV modules. One of them is the well-known incremental conductance (IncCond) algorithm [20,21]. This method consists in the regulation of the PV voltage according to the MPP voltage reference. At each iteration, the PV voltage reference is adjusted based on the comparison of the incremental conductance $(\mathrm{dI} / \mathrm{dV})$ of the PV source with the negative instantaneous conductance $(-\mathrm{I} / \mathrm{V})$. The position of the operating point with respect to the MPP on the PV power curve is known based on the following equation [20]:

$$
\left\{\begin{array}{lr}
\frac{d I}{d V}=-\frac{I}{V} & \text { at the } M P P \\
\frac{d I}{d V}>-\frac{I}{V} & \text { at left of the MPP } \\
\frac{d I}{d V}<-\frac{I}{V} & \text { atright of the MPP }
\end{array}\right.
$$

The IncCond method is simple and easy to implement. But, the convergence speed and the steady state power oscillations depend mainly on the size of the step change in the reference voltage. In this paper, a SN-RBFN based controller is applied to overcome the nonlinear issues arising with such MPPTs. The aim is to enhance the dynamic performance and the tracking accuracy of the IncCond algorithm. The MPP of the studied PV generator is tracked through a DC-DC boost converter. As shown in Fig.4a, a PI voltage controller generates the gate signal of the power switch, while the SNRBFN based controller generates the PV voltage reference. The proposed MPPT regulator is based on the principle of the IncCond technique. The learning ability of the SN-RBFN tracker ensures the self-adaptation to any change of operating conditions. The adopted SN-RBFN contains a single hidden node that uses the Gaussian function defined as [22]:

$$
f(x)=\exp \left(-\frac{\|x-c\|^{2}}{2 b^{2}}\right)=h
$$

Where $c$ is the central point of the Gaussian function $f(x), b$ is the width value of $f(x)$, and $x=\left[x_{1}, x_{2}, x_{3}\right]$ is the input vector and \| $\|$ denotes the Euclidean norm. The SN-RBFN output (y) is calculated as:

$$
y=V_{\text {pvref }}=a_{0}+a_{1} f(x)
$$

Where $a_{0}$ and $a_{l}$ are the bias and the weight of the SN-RBFN respectively, and $V_{\text {pvref }}$ is the $\mathrm{PV}$ voltage reference at the output of MPPT controller. The SN-RBFN's inputs are: the instantaneous conductance $(I / V)$, the incremental conductance $(\Delta I / \Delta V)$, and the reference voltage error $\left(\Delta V_{\text {pvref }}(k)=V_{\text {pvref }}(k)\right.$ $\left.V_{\text {pvref }}(k-1)\right)$. In this paper, a supervised learning rule based gradient descent method [11,23] is adopted for the online update of the SN-RBFN parameters. The objective function used for the weights adaptation is defined as:

$$
\sigma(k)=e_{y}(k)^{2} / 2=\left(y_{d}-y\right)^{2} / 2
$$

Where $e_{y}$ is the output error, and $y_{d}$ is the desired output voltage. The goal of the online learning process of the SN- 
RBFN is to minimize the performance index function $\sigma(k)$. Thus, the adaptation laws of the $\mathrm{SN}-\mathrm{RBFN}$ gains are given according to the gradient descent method as follows:

$$
\begin{gathered}
a_{i}(k+1)=a_{i}(k)+\Delta a_{i}(k)+\alpha\left(a_{i}(k)-a_{i}(k-1)\right) \\
c_{j 1}(k+1)=c_{j 1}(k)+\Delta c_{j 1}(k)+\alpha\left(c_{j 1}(k)-c_{j 1}(k-1)\right) \\
b(k+1)=b(k)+\Delta b(k)+\alpha(b(k)-b(k-1))
\end{gathered}
$$

Where $\alpha$ is the momentum factor, $k$ is the $\mathrm{k}$-th iteration, $i=0,1$, and $j=1,2,3$. According to the $\mathrm{BP}$ algorithm based on the gradient descent rule, the SN-RBFN parameters $a_{i}, c_{j 1}$ and $b$ are adjusted by computing the gradient of the error function $\sigma(k)$ with respect to the SN-RBFN coefficients, so that $\sigma(k)$ is eliminated. The derivative of the error function $\sigma(k)$ against each SN-RBFN's gain is evaluated by propagating the error term back through the NN. Thus, the SN-RBFN parameters are adjusted using the formulas :

$$
\begin{gathered}
\Delta a_{0}(k)=-\mu \frac{\partial \sigma}{\partial a_{0}}=-\mu \frac{\partial \sigma}{\partial y} \frac{\partial y}{\partial a_{0}}=\mu e_{y}(k) \\
\Delta a_{1}(k)=-\mu \frac{\partial \sigma}{\partial a_{1}}=-\mu \frac{\partial \sigma}{\partial y} \frac{\partial y}{\partial a_{1}}=\mu e_{y}(k) f(x) \\
\Delta c_{j 1}(k)=-\mu \frac{\partial \sigma}{\partial c_{j 1}}=-\mu \frac{\partial \sigma}{\partial y} \frac{\partial y}{\partial h} \frac{\partial h}{\partial c_{j 1}}=\mu a_{1} e_{y}(k)\left(x_{j}-c_{j 1}\right) f(x) / b^{2} \\
\Delta b(k)=-\mu \frac{\partial \sigma}{\partial b}=-\mu \frac{\partial \sigma}{\partial y} \frac{\partial y}{\partial h} \frac{\partial h}{\partial b}=\mu a_{1} e_{y}(k)\|x-c\|^{2} f(x) / b^{3}
\end{gathered}
$$

Where $\mu$ denotes the learning rate. We define the variable $G_{\text {in }}(k)=(I(k) / V(k))+(\Delta I(k) / \Delta V(k))$ that has to be equal to zero at the MPP. Since the desired output of SN-RBFN based MPPT controller $\left(y_{d}\right)$ is unknown, the error $e_{G}(k)=\left(0-G_{i n}(k)\right)$ is used instead of $e_{y}(k)$ in Eq.17-20. Thus, the iterative learning algorithm of the SN-RBFN based MPPT controller is given as:

$\left\{\begin{array}{c}a_{0}(k+1)=a_{0}(k)+\mu G_{i n}(k)+\alpha\left(a_{0}(k)-a_{0}(k-1)\right) \\ a_{1}(k+1)=a_{1}(k)+\mu G_{i n}(k) f(x)+\alpha\left(a_{1}(k)-a_{1}(k-1)\right) \\ c_{j 1}(k+1)=c_{j 1}(k)+\mu a_{1} G_{i n}(k)\left(x_{j}-c_{j 1}\right) f(x) / b^{2}+\alpha\left(c_{j 1}(k)-c_{j 1}(k-1)\right) \\ b(k+1)=b(k)+\mu a_{1} G_{i n}(k)\|x-c\|^{2} f(x) / b^{3}+\alpha(b(k)-b(k-1))\end{array}\right.$

Once the term $G_{\text {in }}(k)$ converges to zero, the SN-RBFN stabilizes at the reached operating power point that correspond to the MPP of PV source at the given climatic condition.

\section{B. Predictive torque control for the PMSG}

The block diagram of the control scheme of the AC-DC converter used for the PMSG is depicted in Fig.4.b. A DPCM based on the Deadbeat approach [24-26] is applied to drive the AC-DC rectifier in order to improve the dynamic performance of the classical direct torque control scheme of PMSG. Besides, an ADALINE based MPPT controller is proposed for the tight regulation of the rotating speed of WT. The main tasks of the PMSG control system are to instantaneously follow the MPP of WT generator, to track the electromagnetic torque reference, and to maintain the direct stator current component close to zero.

The basic idea of the adopted DPCM is to compute, at each sampling period, and apply the optimal stator voltage vector that ensures the minimization, at the next sampling instant, of the tracking errors between the predicted and the reference values of the controlled variables [24,25]. Using the calculated voltage vector, the proper switching pulses for rectifier are generated through the Space-Vector Modulator (SVM).

\section{- $\quad$ Discrete time model}

The model of the PMSG developed in the rotating $d q$ frame is used to predict the future values of the controlled variabes, which are the electromagnetic torque $T_{e}$ and the direct stator current $I_{s d}$. Then, the reference stator voltage components $V_{s d}$ and $V_{s q}$ that should be generated during one sampling period are calculated in function of the tracking errors of the regulated quantities $T_{e}$ and $I_{s d}$. The stator flux magnitude of PMSG is indirectly controlled using the d-axis current component.

Thus, the continuous-time model represented by Eq. 2 is discretized using the Euler forward method, such that the current derivatives are approximated as [27]:

$$
\frac{d I}{d t} \approx \frac{I(k+1)-I(k)}{T_{S}}
$$

Where $T_{S}$ is the sampling period, $k$ and $k+1$ are the actual and future sampling instants, respectively. The future values of d-axis and q-axis components of stator current are expressed using Eq. 2 and Eq.22 as follows:

$\left\{\begin{array}{c}I_{s d}(k+1)=\frac{T_{s}}{L_{s}}\left[-V_{s d}(k)-R_{s} I_{s d}(k)+L_{s} \omega_{e} I_{s q}(k)+\frac{L_{s}}{T_{s}} I_{s d}(k)\right] \\ I_{s q}(k+1)=\frac{T_{s}}{L_{s}}\left[-V_{s q}(k)-R_{s} I_{s q}(k)-L_{s} \omega_{e} I_{s d}(k)+\omega_{e} \phi+\frac{L_{s}}{T_{s}} I_{s q}(k)\right]\end{array}\right.$

The linear relationship between the q-axis stator current and the generator torque of Eq.4 can be rewritten as:

$$
I_{s q}=\frac{2}{3 p \phi} T_{e}
$$

By replacing Eq.24 in Eq. 23, we found :

$$
\left\{\begin{array}{c}
I_{s d}(k+1)=\frac{T_{s}}{L_{s}}\left[-V_{s d}(k)-R_{s} I_{s d}(k)+\frac{2}{3 p \phi} L_{s} \omega_{e} T_{e}(k)\right]+I_{s d}(k) \\
T_{e}(k+1)=\frac{3 p \phi T_{s}}{2 L_{s}}\left[-V_{s q}(k)-\frac{2 R_{s}}{3 p \phi} T_{e}(k)-L_{s} \omega_{e} I_{s d}(k)+\omega_{e} \phi\right]+T_{e}(k)
\end{array}\right.
$$

According to deadbeat principle [26], the predictive control target here is to get, at the next sampling instant $(\mathrm{k}+1)$, both predicted values of the generator torque and d-axis current component ideally equal to their respective references:

$$
\left\{\begin{array}{c}
T_{e}^{*}(k+1)=T_{e}(k+1) \\
I_{s d}^{*}(k+1)=I_{s d}(k+1)
\end{array}\right.
$$

By substituting Equ.26 in Equ.25, we obtain:

$$
\left\{\begin{array}{c}
I_{s d}^{*}(k+1)=\frac{T_{s}}{L_{s}}\left[-V_{s d}(k)-R_{s} I_{s d}(k)+\frac{2}{3 p \phi} L_{s} \omega_{e} T_{e}(k)\right]+I_{s d}(k) \\
T_{e}^{*}(k+1)=\frac{3 p \phi T_{s}}{2 L_{s}}\left[-V_{s q}(k)-\frac{2 R_{s}}{3 p \phi} T_{e}(k)-L_{s} \omega_{e} I_{s d}(k)+\omega_{e} \phi\right]+T_{e}(k)
\end{array}\right.
$$

Since the d-axis current reference $I_{s d}{ }^{*}$ is constantly zero, it can be assumed that the present setpoint of d-axis current is equal to the future reference [26]:

$$
I_{s d}^{*}(k+1)=I_{s d}^{*}(k)
$$

On the other hand, as shown in Fig 4.b, the external speed control loop provides the actual torque set point $T_{e}{ }^{*}(k)$. Assuming that the tracking error of the rotational speed is constant during two successive sampling period, the future reference value of $T_{e}$ at the instant $(k+1)$ is estimated using the linear Lagrange extrapolation [24,27] as presented in Fig4.c. Thus, the future torque reference is calculated as :

$$
T_{e}^{*}(k+1)=2 T_{e}^{*}(k)-T_{e}^{*}(k-1)
$$


Substituting Eq.29 and Eq.28 in Eq.27, the d-axis and q-axis components of the required stator voltage vector are given as:

$\left\{\begin{array}{c}V_{s d}(k)=-R_{s} I_{s d}(k)+\frac{2}{3 p \phi} L_{s} \omega_{e} T_{e}(k)-\frac{L_{s}}{T_{s}} \Delta I_{s d}(k) \\ V_{s q}(k)=-\frac{2 R_{s}}{3 p \phi} T_{e}(k)-L_{s} \omega_{e} I_{s d}(k)+\omega_{e} \phi-\frac{2 L_{s}}{3 p \phi T_{s}}\left(\Delta T_{e}(k)+d T_{e}^{*}(k)\right)\end{array}\right.$

Where $\Delta T_{e}(k)$ and $\Delta I_{s d}(k)$ are the instantaneous tracking errors of the torque and the d-axis current, respectively. While, $d T_{e}{ }^{*}(k)$ is the current variation in the torque reference:

$$
\left\{\begin{array}{c}
\Delta I_{s d}(k)=I_{s d}^{*}(k)-I_{s d}(k) \\
\Delta T_{e}(k)=T_{e}^{*}(k)-T_{e}(k) \\
d T_{e}^{*}(k)=T_{e}^{*}(k)-T_{e}^{*}(k-1)
\end{array}\right.
$$

- $\quad$ ADALINE based speed controller

Traditionally, a Proportional Integral (PI) controller is used to regulate the rotating speed of WT in order to extract the maximum wind energy. However, a PI controller with fixed gains for a time-varying WEGS, which is subject to random wind speed and parameters variations, can yield to poor dynamic performance. To overcome this drawback, an adaptive ADALINE (ADaptive LInear NEuron) network based controller is adopted in this paper, to control the rotational speed by producing the reference for the electromagnetic torque. The ADALINE based speed controller consists of a single neuron with linear activation function, where the output is calculated as $[13,28]$ :

$$
y_{w}(k)=T_{e}^{*}(k)=\sum_{i=1}^{n=3} x_{i}(k) w_{i}(k)=X_{\omega}^{T} \cdot W_{\omega}
$$

Where $w_{i}$ is the $\mathrm{i}^{\text {th }}$ weight coefficient $(i=1,2,3), x_{i}$ is the $\mathrm{i}^{\text {th }}$ input signal and $n$ is the number of inputs. $X_{\omega}$ and $W_{\omega}$ are the inputs and weights vectors, respectively. The ADALINE output is the electromagnetic torque reference $T_{e}{ }^{*}(k)$, while the inputs are the measured speed at the instant $k \omega_{e}(k)$, the actual speed error $e_{\omega}(k)=\omega_{e}{ }^{*}(k)-\omega_{e}(k)$, and the previous error $e_{\omega}(k-1)$. Such that $\omega_{e}{ }^{*}(k)$ is the speed reference. The Widrow-Hoff Least Mean Square (LMS) learning algorithm [28] is used for the online update of the ADALINE's weights. Where, the goal of the self-learning process of the ADALINE based speed controller is to minimize the mean square of the instantaneous error $e_{\omega}(k)$. Using the transformation $X^{\prime}=0.5 \operatorname{sgn}\left(X_{\omega}\right)+$ $0.5 X_{\omega}$ [28], the weight vector is adjusted as:

$$
W_{\omega}(k+1)=W_{\omega}(k)+\alpha_{\omega} \frac{e_{\omega}(k) X^{\prime}}{\lambda+\left\|X^{\prime}\right\|^{2}}
$$

Where $W_{\omega}(k+1)$ and $W_{\omega}(k)$ are the weight vectors at the next and present iteration, $k+1$ and $k$, respectively. $\lambda$ is a correction factor, $\alpha_{\omega}$ is the learning rate, and $\left\|X^{\prime}\right\|^{2}$ is the squared norm of the input vector $X^{\prime}$. The learning coefficient $\alpha_{\omega}$ which has a value in the interval $[0.1,1]$ affect considerably the speed of convergence to the optimal weighting factors of the ADALINE network. The continuous adjustment of the ADALINE's weights using the normalized LMS law of Equ.33, ensures the self-adaptation of the adopted speed controller to any change of working conditions unlike the PI regulator with fixed gains .

\section{Control of the SOFC stack}

As depicted in Fig.4.d, an ADALINE based power controller with two adaptive weights regulates the SOFC's output power to follow the power reference provided by the central power supervisor. The inputs of the ADALINE controller are the power error $\left(e_{f_{c}}(k)=P_{f_{c}}(k)-P_{f_{c}}^{*}(k)\right)$, and the change of error $\left(d e_{f_{c}}(k)=e_{f_{c}}(k)-e_{f_{c}}(k-1)\right)$. Such that, $P_{f_{c}}{ }^{*}(k)$ and $P_{f_{c}}(k)$ are the power reference and the output power generated by the SOFC stack, respectively. Whereas, the output is the duty cycle $D_{f c}(k)$ that controls the commutation time of the switching device of the boost converter. The control error $E_{f c}(k)$ used for the online learning process of the SOFC's power controller is defined in function of the sliding surface $S_{f c}(k)$ as:

$$
E_{f c}(k)=0-S_{f c}(k)=-\left[\lambda_{1} \cdot e_{f c}(k)+d e_{f c}(k)\right]
$$

Where $\lambda_{1}$ is a positive constant. According to the SMC principle [29], the control goal here is to maintain the trajectory of the state variable, which is the SOFC's output power, on the sliding surface $S_{f c}(k)=0$ for the whole time. With reference to the LMS algorithm [13], the weight vector $\left(W_{f c}\right)$ of the SOFC's controller is updated at each iteration of the online training process as follows:

$$
W_{f c}(k+1)=W_{f c}(k)+2 \alpha_{2} E_{f c}(k) X_{f c}(k)
$$

Where $X_{f c}$ is the input vector and $\alpha_{2}$ is the learning rate of the SOFC's controller. In this case, the connective weights are adapted in such way that the sliding surface $S_{f c}(k)$ tend to zero, so that the power tracking error will be eliminated.

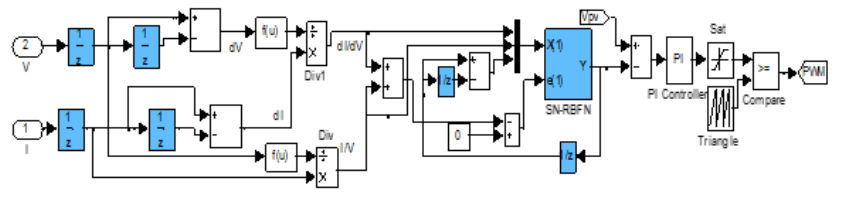

(a)

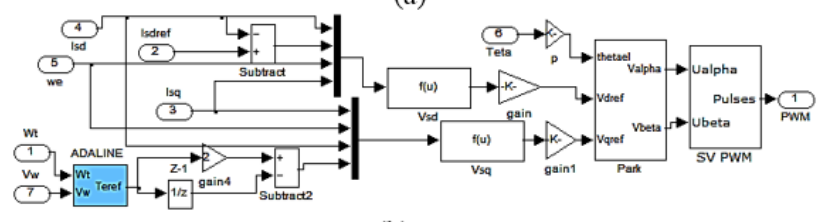

(b)

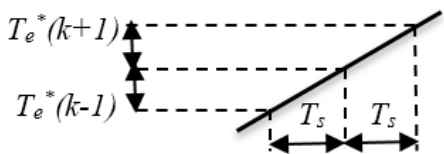

(c)

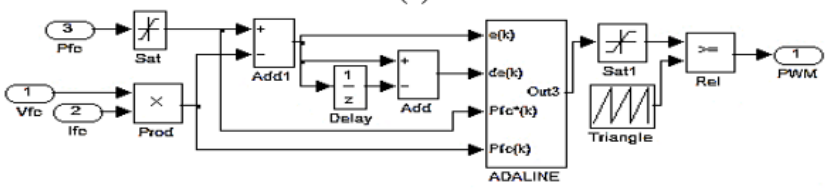

(d)

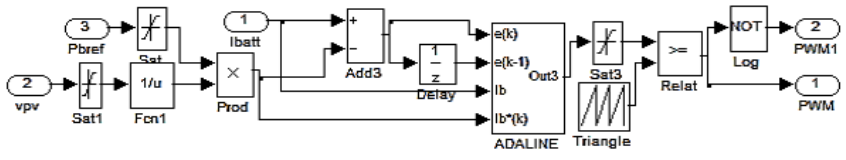

(e)

Fig. 4. a) SNRBN based PV controller, b) control scheme of WEGS, c) Estimation of future value of torque [24], d) SOFC's controller, and e) BESS's controller. 


\section{Control of the BESS}

The control of the charge and discharge of BESS is performed through a bidirectional DC-DC converter. As shown in Fig.4.e, the BESS power reference $P^{*}$, provided by the PMS, is divided by the BESS terminal voltage to generate the current set point $I_{b}^{*}$. Then, an ADALINE based controller is used to regulate the BESS's output current $I_{b}$ to follow its setpoint $I_{b}{ }_{b}$. The inputs of the BESS's ADALINE regulator are the actual BESS current error $e_{b}(k)$ and the past current error $e_{b}(k-1)$. Whereas, the output is the duty cycle $D_{b}(k)$ of the PWM control signal of the buck-boost converter. Such that, the present current error $e_{b}(k)$ is defined as the difference between the current reference $I_{b}^{*}(k)$ and the measured BESS current $I_{b}(k)$. The control objective used for the adaptation of the gains is expressed in term of the sliding surface $S_{b}(k)$ as:

$$
E_{b}(k)=0-S_{b}(k)=-\left[\lambda_{2} \cdot e_{b}(k)+d e_{b}(k)\right]
$$

Where $E_{b}(k)$ is the error term used for the weights update, $d e_{b}(k)=e_{b}(k)-e_{b}(k-1)$ is the change of the BESS current error, and $\lambda_{2}$ is a positive constant. Where, the ADALINE's weights vector $W_{b}$ are online adjusted via a LMS-rule as follows:

$$
W_{b}(k+1)=W_{b}(k)+2 \alpha_{3} E_{b}(k) X_{b}(k)
$$

Where $X_{b}$ and $\alpha_{3}$ are, respectively, the input vector and the learning rate of the BESS's controller. If the sliding function $S_{b}(k)$ in the steady state, is close to zero, that means that the trajectory of the BESS's current $I_{b}$ is forced to stay on it.

\section{E. Control of the FEC}

A Virtual Flux based Direct Power Control [30] scheme is applied for the control of the FEC. Assuming that the grid voltage vector $\underline{u}_{g}$ and the inductance filter $L$ are virtual $\mathrm{AC}$ motor quantities, the grid VF voltage $\underline{\Psi}_{g}$ is defined as:

$$
\underline{\Psi}_{g}=\int \underline{u}_{g} d t=\int \underline{u}_{c}-R \underline{i}_{c}-L \frac{d \underline{i}_{c}}{d t} d t
$$

$\underline{u}_{c}$ is the inverter voltage vector and $\underline{i}_{c}$ is the FEC output current vector. The voltage drop across the filter resistance $\mathrm{R}$ is neglected. In the stationary $\alpha \beta$ frame, the $\alpha \beta$ components of the grid VF are calculated in term of the inverter switching states $\left(S_{a}, S_{b}, S_{c}\right)$, the $\alpha \beta$ current components $\left(i_{c \alpha}, i_{c \beta}\right)$ and the measured DC-link voltage $V_{D C}$ :

$$
\left\{\begin{array}{c}
\Psi_{g \alpha}=\int \frac{V_{D C}}{3}\left(2 S_{a}-S_{b}-S_{c}\right) d t-L i_{c \alpha} \\
\Psi_{g \beta}=\int \frac{V_{D C}}{\sqrt{3}}\left(S_{b}-S_{c}\right) d t-L i_{c \beta}
\end{array}\right.
$$

Based on the grid VF components $\Psi_{g \alpha, \beta}$, the instantaneous active and reactive power $(\mathrm{P}, \mathrm{Q})$ can be estimated as [30]:

$$
\left\{\begin{array}{l}
P=\frac{3}{2} \omega \cdot\left(\Psi_{g \alpha} i_{c \beta}-\Psi_{g \beta} i_{c \alpha}\right) \\
Q=\frac{3}{2} \omega \cdot\left(\Psi_{g \alpha} i_{c \alpha}+\Psi_{g \beta} i_{c \beta}\right)
\end{array}\right.
$$

In a conventional DPC scheme, PI controllers are used to control the DC-bus voltage as well as the active and reactive power flows. However, the irregular RESs power generation and the time-varying load demand require that the FEC works dynamically over a wide range of $\mathrm{MG}$ operation. For this purpose, NN based controllers are used in the adopted VFDPC scheme instead of the linear PI controllers in order to improve the dynamic performance and to react adaptively to the varying conditions. As depicted in Fig.5, a FFNN is employed for the outer DC voltage control loop, while ENNs based controllers are applied for the power control loops. The Adaptive Interaction algorithm proposed by Brandt and Lin [31] is used for the online weights adaptation of the proposed FFNN and ENN controllers.

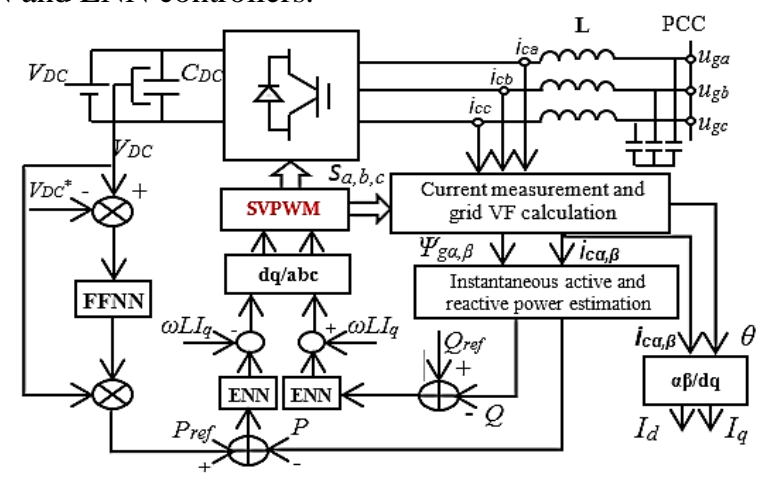

Fig. 5. VF-DPC scheme of the FEC.

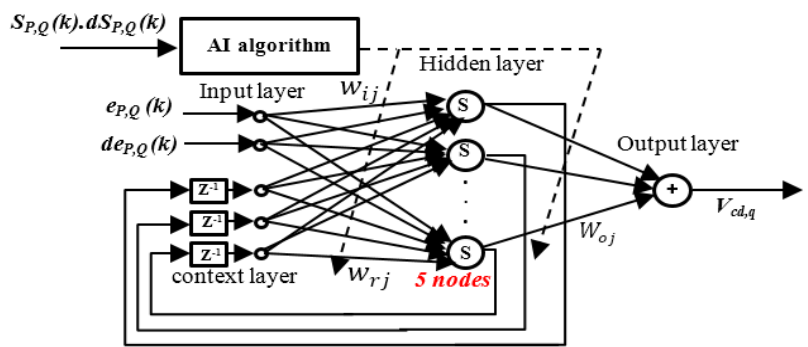

(a)

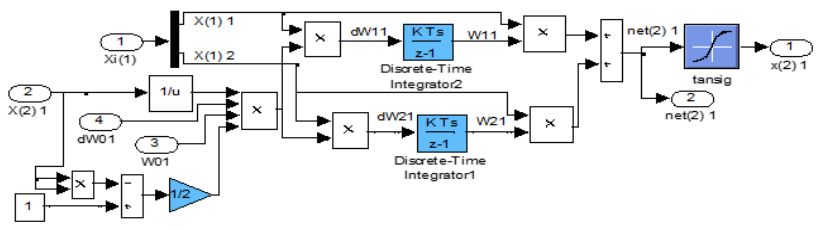

(b)

Fig. 6. a) Architecture of the ENN based power controller, b) a exemple of the simulink block used for FFNN weights adaptation with AI rule.

\section{- $\quad$ The principle of the AI algorithm for NN training}

The adjustment of the NN weights with the adaptive interaction algorithm is equivalent but simpler than the wellknown BP approach. Moreover, it does not need to back propagate the output error through the network [31]. The most prominent features of the AI approach are the adaptation during the interaction of neurons and the low computational requirements in comparison to the $\mathrm{BP}$ algorithm. In this subsection, the $\mathrm{NN}$ weights adaptation law based on the AI algorithm is given. The output of each node in the 1-th layer of a $\mathrm{NN}$ is calculated as:

$$
x_{n}^{(l)}=f_{n}^{(l)}\left(n e t_{n}^{(l)}\right)=f_{n}^{(l)}\left(\sum_{i=1}^{N} w_{i} x_{i}^{(l-1)}\right)
$$

Where $x_{n}{ }^{(l)}$ and $f_{n}{ }^{(l)}$ are the output and the activation function of the n-th node in the 1-th layer respectively, $x_{i}^{(l-1)}$ is i-th input of $\mathrm{n}$-th node, $w_{i}$ is the connection weight from $\mathrm{i}$-th input to the $\mathrm{n}$ th node, and $N$ is the number of inputs to the l-th layer. The training process aims to minimize the cost function $E$ expressed as [13]:

$$
E=\frac{1}{2} \sum_{n=1}^{m} e_{n}^{2}
$$


Where $\quad e_{n}=\left\{\begin{array}{cr}x_{n}^{(l)}-d_{n} & \text { for output node } \\ 0 & \text { otherwise }\end{array}\right.$

$m$ is the number of the output neurons. $d_{n}$ is the desired output of the n-th output neuron. The weights of the NN can be dynamically updated according to the AI law $[13,31]$ as follows:

$$
\Delta w_{i}=f_{n}^{(l)^{\prime}}\left(n e t_{n}^{(l)}\right) \frac{x_{i}^{(l-1)}}{x_{n}^{(l)}} \sum_{j=1}^{P} w_{o j} \Delta w_{o j}-\gamma f_{n}^{(l)^{\prime}}\left(n e t_{n}^{(l)}\right) x_{i}^{(l-1)} e_{n}
$$

Where $\gamma>0$ is the adaptation coefficient and $P$ is the number neurons in the next layer. $w_{o j}$ is the weight connecting o-th with $\mathrm{j}$-th neuron. The Tangent-Sigmoid Activation Function (TS$\mathrm{AF})$ of neurons is defined as:

$$
x_{n}^{(l)}=f_{n}^{(l)}\left(n e t_{n}^{(l)}\right)=\frac{2}{1+e^{-n e t_{n}^{(l)}}}-1=\frac{1-e^{-n e t_{n}^{(l)}}}{1+e^{-n e t_{n}^{(l)}}}
$$

The time derivative of TS-AF is so calculated as:

$$
f_{n}^{(l)}\left(n e t_{n}^{(l)}\right)=\frac{1}{2}\left(1-\left(x_{n}^{(l)}\right)^{2}\right)
$$

\section{- ENN based power controllers}

The proposed ENN based power controller shown in Fig.6.a consist of four layers [32]: the IL, the HL, the CL, and the OL. The neurons in the CL known as memory units store the previous outputs of the hidden neurons that offer better learning efficiency. The inputs of ENN based active power controller are the tracking error $e_{P}(k)=P^{*}(k)-P(k)$ and its derivative $d_{P}(k)=e_{P}(k)-e_{P}(k-1)$ whereas, its output is the $q$-axis component of the control voltage vector $\left(V_{c q}\right)$. Further, the inputs of the reactive power ENN controller are the error $e_{Q}(k)=Q^{*}(k)-Q(k)$ and the change of error $d e_{Q}(k)=e_{Q}(k)-e_{Q}(k-$ $1)$, while the output is the d-axis component of the inverter voltage vector $\left(V_{c d}\right)$. The TS-AF is used for the neurons of the $\mathrm{HL}$ and OL of the ENNs.The basic function of each layer is described as follows:

1) The output of each node in the IL is defined as:

$$
x_{i}^{(1)}(k)=f_{i}^{(1)}\left(n e t_{i}^{(1)}\right)=n e t_{i}^{(1)}, \quad i=1,2
$$

$k$ is the k-th iteration and $n e t_{i}^{(1)}$ is the input of the i-th node.

2) The output of the Hidden layer's neurons is:

$x_{j}^{(2)}(k)=f_{j}^{(2)}\left(n e t_{j}^{(2)}\right)=f_{j}^{(2)}\left(\sum_{r} w_{r j} x_{r}^{(3)}(k)+\sum_{i} w_{i j} x_{i}^{(1)}(k)\right)$

Where $x_{j}^{(2)}$ is the output of the $\mathrm{j}$-th node in HL, $w_{i j}$ are the connective weights from the input nodes to hidden nodes, $x_{r}^{(3)}(k)$ is the output of the CL, $w_{r j}$ are the connective weight from the hidden neurons to the context neurons, and $f_{j}^{(2)}$ is the TS-AF in the HL.

3) The feedback from the HL to the CL input is described as:

$$
x_{r}^{(3)}(k)=x_{j}^{(2)}(k-1)
$$

4) The output signal from the Output Layer is calculated as:

$$
x_{o}^{(4)}(k)=f_{o}^{(4)}\left(n e t_{o}^{(4)}\right)=f_{o}^{(4)}\left(\sum_{j} w_{j o} n e t_{j}^{(2)}(k)\right)
$$

Where $x_{o}^{(4)}$ is the network output, $f_{o}^{(4)}$ is the TS-AF, and $w_{j o}$ are the weights connection between the HL and the OL. The ENN weights are online adjusted based on the AI law (of Eq.44), by tacking into account the Eq.46, as follows :
$\left\{\begin{array}{l}\Delta w_{i j}(k)=\frac{1}{2}\left[1-\left(x_{j}^{(2)}\right)^{2}\right] \frac{x_{i}^{(1)}}{x_{j}^{(2)}} w_{o j} \Delta w_{o j} \text { weights between } I L \text { and } H L \\ \Delta w_{r j}(k)=\frac{1}{2}\left[1-\left(x_{j}^{(2)}\right)^{2}\right] \frac{x_{r}^{(3)}}{x_{j}^{(2)}} w_{o j} \Delta w_{o j} \text { weights between } C L \text { and } H L(51) \\ \Delta w_{o j}(k)=-\frac{\gamma}{2}\left[1-\left(x_{o}^{(3)}\right)^{2}\right] x_{j}^{(2)} e_{n} \quad \text { weights between } H L \text { and } O L\end{array}\right.$

The invariance condition $S_{P, Q}(k) \cdot d S_{P, Q}(k)=0$ that should be satisfied in the sliding mode is considered for the training algorithm of the ENN based power controller as suggested in [33].Thus, the term $S_{P, Q}(k) \cdot d S_{P, Q}(k)$ is used instead of the output error $e_{n}$ in the adaptation law of ENN of Equ.51, where:

$$
\left\{\begin{array}{l}
S_{P, Q}(k)=\lambda_{3} \cdot e_{P, Q}(k)+d e_{P, Q}(k) \\
d S_{P, Q}(k)=S_{P, Q}(k)-S_{P, Q}(k-1)
\end{array}\right.
$$

Where $S_{P, Q}$ and $d S_{P, Q}$ are the sliding surface and its derivative for, respectively, the active and reactive powers $(P$ and Q). $\lambda_{3}$ is a positive constant. The control goal of the proposed ENNs is to drive the state variables $P$ and $Q$ to the sliding surfaces $S_{P}$ and $S_{Q}$ respectively, in finite time.

\section{- FFNN based DC voltage controller}

The three-layer FFNN [31] described by Eq.53 controls the DC-bus voltage. The tracking error of the DC voltage $e_{V}(k)=$ $V_{D C}{ }^{*}(k)-V_{D C}(k)$ and the previous error $e_{V}(k-1)$ represent the inputs of the adopted FFNN.

$$
\left\{\begin{array}{c}
x_{i}^{(1)}(k)=f_{i}^{(1)}\left(\text { net }_{i}^{(1)}\right)=n e t_{i}^{(1)} \\
x_{j}^{(2)}(k)=f_{j}^{(2)}\left(\text { net }_{j}^{(2)}\right)=f_{j}^{(2)}\left(\sum_{i} w_{i j} x_{i}^{(1)}(k)\right) \\
x_{o}^{(3)}(k)=f_{o}^{(3)}\left(\text { net }_{o}^{(3)}\right)=f_{o}^{(3)}\left(\sum_{j} w_{o j} x_{j}^{(2)}(k)\right)
\end{array}\right.
$$

Where $n e t_{i}^{(1)}$ is the $\mathrm{i}$-th input of FFNN, $x_{i}^{(1)}(k)$ is the $\mathrm{i}$-th output of the IL, $x_{j}^{(2)}(k)$ is the output of the HL, net $t_{o}^{(3)}$ is the input of the output neuron, $x_{o}^{(3)}(k)$ is the output of FFNN, $w_{i j}$ means the weight between the i-th node of the IL and j-th node of the HL, $w_{o j}$ is the weight connecting the $\mathrm{j}$-th node of the HL to the OL, and $f_{j}^{(2)}, f_{o}^{(3)}$ are the TS-AFs for the HL and the OL respectively. The control output signal of the FFNN is multiplied by the measured DC-bus voltage to determine the active power reference $P^{*}(k)$. As depicted in Fig.6.b, the FFNN weights are online adapted according to the AI rule using the following:

$\left\{\begin{array}{l}\Delta w_{i j}(k)=\frac{1}{2} \frac{\left[1-\left(x_{j}^{(2)}\right)^{2}\right]}{x_{j}^{(2)}} x_{i}^{(1)} w_{o j} \Delta w_{o j} \text { weights between } I L \text { and } H L \\ \Delta w_{o j}(k)=-\frac{\gamma}{2}\left[1-\left(x_{o}^{(3)}\right)^{2}\right] x_{j}^{(2)} e_{n} \text { weights between } H L \text { and } O L\end{array}\right.$

The error $e_{n}$ between the desired and estimated output, in Eq.54, is replaced by the term $S_{V}(k)+d S_{V}(k)$ such that:

$$
\left\{\begin{array}{l}
S_{V}(k)=\lambda_{4} \cdot e_{V}(k)+d e_{V}(k) \\
d S_{V}(k)=S_{V}(k)-S_{V}(k-1)
\end{array}\right.
$$

$\lambda_{4}$ is a positive constant. $S_{V}$ and $d S_{V}$ are, respectively, the sliding surface and its derivative for the DC-link voltage control.

\section{F. Fuzzy Logic based Power Management System}

A centralized PMS is used in order to minimize the power flow from the electric grid. For several conditions of power generation and demand, it imposes the power references for the power converters interfacing the SOFC and BESS. The 
SOC of BESS should be maintained in secure range $\left[S O C_{\min }\right.$ $\left.S O C_{\max }\right]$. The power supervision process begins from the calculation of the net power value $P_{\text {net }}$ as:

$$
P_{\text {net }}=P_{R E S}-P_{L}=\left(P_{P V}+P_{W T}\right)-\left(P_{L a c}+P_{L d c}\right)
$$

Where $P_{R E S}$ is the power produced by the RESs, $P_{L}$ is the total load demand, $P_{P V}$ is the power produced by the PV source, $P_{W T}$ is the power provided by the WT, $P_{L d c}$ and $P_{L a c}$ are the DC and AC loads demand. The FEC injects power to the electric grid only when the renewable power generation exceeds the loads demand and the BESS is fully charged $\left(S O C>S O C_{\max }\right)$. If the load demand is greater than the available RESs power, the SOFC and the BESS contribute to cover the energy shortage. In the case where $\mathrm{SOC}<S O C_{\text {min }}$, the SOFC feeds the loads and guarantees the charge of the BESS. Vice versa, if $S O C>S O C_{\min }$ and the power demand exceeds the SOFC rated power, the BESS starts to discharge in order to feed the loads. Otherwise, the needed power comes from the electric grid, if the demand surpasses the rated power of the MG. A Mamdani inference system [34] based fuzzy logic controller calculates the power references $\left(P_{f c}{ }^{*}, P_{b}{ }^{*}\right)$ for the local controllers of FC and BESS. The PMS has two inputs and two outputs: the inputs are $P_{n e t}$ and SOC, while the outputs are the set points for the BESS and the SOFC controllers. The fuzzy rule table of the PMS, proposed to decide the power setpoints $P_{f_{c}}{ }^{*}$ and $P_{b}{ }^{*}$, are given in Table. I.

TABLE I. FUZZY RULES FOR $P{ }^{*}$ AND $P_{\mathrm{FC}}{ }^{*}$ DURING BOTH PERIODS OF POWER LACK AND EXCESS

\begin{tabular}{|c|c|c|c|c|c|c|}
\hline $\mathrm{SOC}^{\mathrm{P}_{\text {net }}}$ & NM & NS & PS & PM & PB & $\mathrm{PB}+$ \\
\hline$\overline{\mathrm{H}}$ & ZE/- & ZE/- & $\mathrm{PB} /-$ & PS/PM & $\mathrm{PB} / \mathrm{PB}$ & $\mathrm{PB} / \mathrm{PB}$ \\
\hline M & NB/- & NS/- & ZE/PS & ZE/PB & PS/PB & $\mathrm{PB} / \mathrm{PB}$ \\
\hline $\mathrm{L}$ & NB/- & NS/- & NB/PM & NS/PB & NS/PB & $\mathrm{NS} / \mathrm{PB}$ \\
\hline
\end{tabular}

Linguistic terms assigned to the fuzzy sets mean: Negative Medium (NM), Negative Small (NS), ZEro (ZE), Positive Small (PS), Positive Medium (PM), Positive Big (PB), and Positive very Big (PB+). H, L, M mean High, Low, and Medium membership functions, respectively.

TABLE II. SIMULATION PARAMETERS

\begin{tabular}{llc}
\hline \hline \multirow{2}{*}{ Symbol } & \multicolumn{1}{c}{ Description } & Value \\
& \multicolumn{1}{c}{ PMSG parameters } \\
$R_{s}$ & Stator resistance & 0.00829 \\
$L_{s d}, L_{s q}$ & d and q stator inductance & $0.174 \mathrm{mH}$ \\
$\phi$ & Permanent magnet flux & $0.071 \mathrm{wb}$ \\
$\mathrm{p}$ & Number of pole pairs & $6 \mathrm{pair}$ \\
$\mathrm{J}$ & System Inertia & $0.089 \mathrm{~kg} \cdot \mathrm{m}^{2}$ \\
& $\quad$ BPMSX120 PV module parameters \\
$\mathrm{V}_{\mathrm{OC}}$ & Open circuit voltage & $42.1 \mathrm{~V}$ \\
$\mathrm{I}_{\mathrm{SC}}$ & Short circuit current & $3.87 \mathrm{~A}$ \\
$\mathrm{~V}_{\mathrm{MPP}}$ & MPP voltage & $33.7 \mathrm{~V}$ \\
$I_{M P P}$ & MPP current & $3.56 \mathrm{~A}$ \\
$K$ & Boltzmann constant & $1.38 \times 10^{-23} \mathrm{~J} / \mathrm{K}$ \\
$q$ & Electron charge & $1.6 \times 10^{-19} \mathrm{C}$ \\
& $\quad$ Battery bank parameters \\
$Q$ & Rated capacity & $20 \mathrm{Ah}$ \\
$E_{0}$ & Nominal voltage & $240 \mathrm{~V}$ \\
$R_{i n}$ & Internal Resistance & $0.12 \Omega$ \\
\hline \hline
\end{tabular}

\section{SimULATION RESULTS}

In order to demonstrate the effectiveness of the proposed control structure, the operation of the MG has been tested in the Matlab/Simulink environment for different climatic conditions and loads demand. The main simulation parameters are listed in Table. II. The DC loads, which are interfaced with the DC-microgrid through power electronic converters, behave as Constant Power Loads (CPLs) [35].

\section{A. Test under variable irradiance and wind speed}

First of all, the investigated MG is tested for variable irradiation level and changing wind speed in order to check the tracking capability of the proposed MPPT controllers. The DC and AC loads demand are fixed to $5 \mathrm{~kW}$ and $20 \mathrm{~kW}$, respectively. The rapid and gradual change in the irradiation level is depicted in Fig.7.a. The variation of the current and voltage at the output of PV source are shown in Fig.7.b and Fig.7.c. The PV reference voltage provided at the output of the SN-RBFN is depicted in Fig.7.d. Further, for the comparaison purpose, the Fig.7.e illustrates the PV output power obtained using both the adopted SN-RBFN controller and the standard IncCond algorithm. It is clear that the adopted neural tracker for PV source performs very well for changing solar irradiation. The correct MPP is rapidly reached for each irradiation level thanks to the online learning process of the SN-RBFN. The convergence time of the SN-RBFN for the insolation level of $1 \mathrm{~kW} / \mathrm{m}^{2}$ is about $38 \mathrm{~ms}$, which is less than the time achieved with the IncCond algorithm (about 92ms). Moreover, as can be seen from Fig.7.e, the power oscillations around the MPP in the steady state are considerably reduced with the SN-RBFN in comparison with the IncCond method. The static power error of the SN-RBFN is (about $0.305 \mathrm{~W}$ ) lower than the static error of the IncCond method $(0.887 \mathrm{~W})$. When a change in the solar irradiance happens, the proposed PV controller converges rapidly and re-tracks accuratly the new MPP as presented in Fig 7.b and 7.c. At the beginning of each step change in irradiance, the online learning process of the SN-RBFN restarts to recalculate the new optimal parameters $\left(a_{i}, c_{j 1}, b\right)$ that justify the presence of a small transient ripples in the voltage reference as shown in Fig7.d.
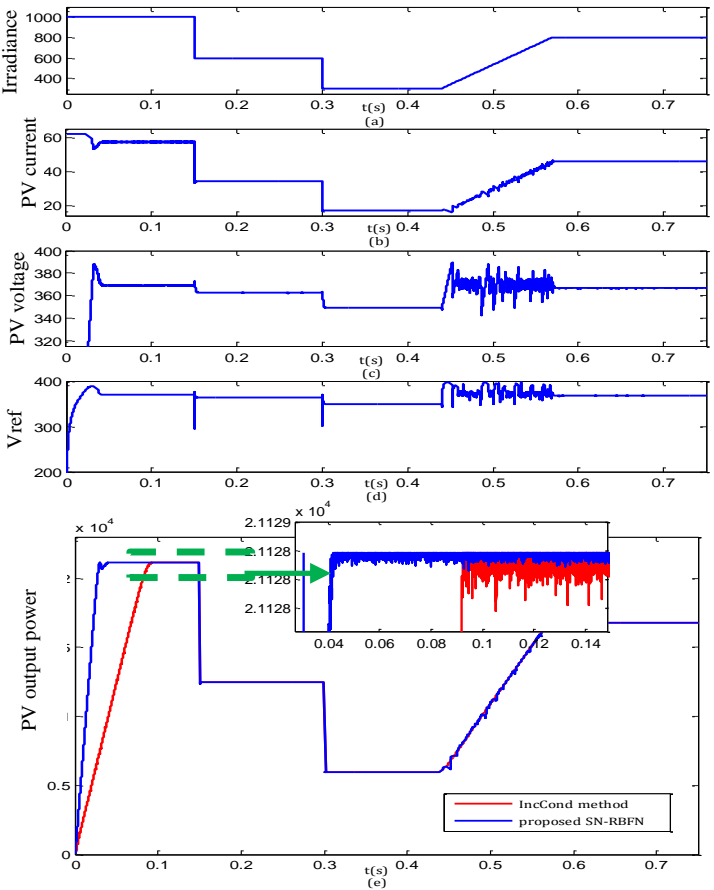

Fig. 7. a) Solar irradiance, b) PV current, $c$ ) $P V$ voltage, d) SN-RBFN output voltage reference e) $\mathrm{PV}$ output power $\left(\mathrm{T}=25^{\circ} \mathrm{C}\right)$. 
In the same test case, the wind speed changes from $12 \mathrm{~m} / \mathrm{s}$ to $10 \mathrm{~m} / \mathrm{s}$ at the instant $0.25 \mathrm{~s}$ then increases to $14 \mathrm{~m} / \mathrm{s}$ at $0.5 \mathrm{~s}$. The obtained results with the applied DPCM are presented in Fig 8. As shown in Fig.8.a, the ADALINE based speed controller outperforms the classical PI controller and offers a shorter response time (about 38ms), an minimal overshoot and closely zero steady-state error during each step change in wind speed. By applying the adequate stator voltage vector, the correct control of the generator torque and d-axis current component $\left(I_{s d}\right)$ is assured for different wind conditions as depicted in Fig.8.b. A fast transient response of the electromagnetic torque is obtained with good steady state characteristic. Further, due to the fixed switching frequency, the torque and flux ripples are considerably reduced as shown in Fig.8.b,c. The FFNN ensures the stabilization of the DC-bus voltage at the desired setpoint as depicted in Fig.8.d regardless of the climatic conditions.
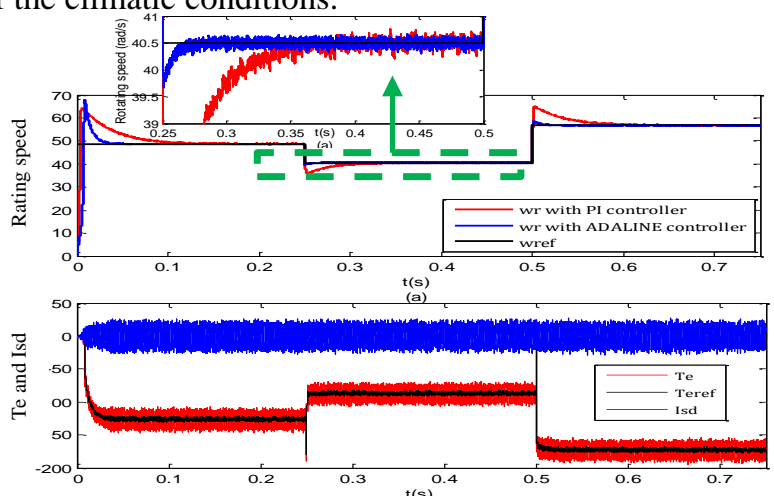

t(s)
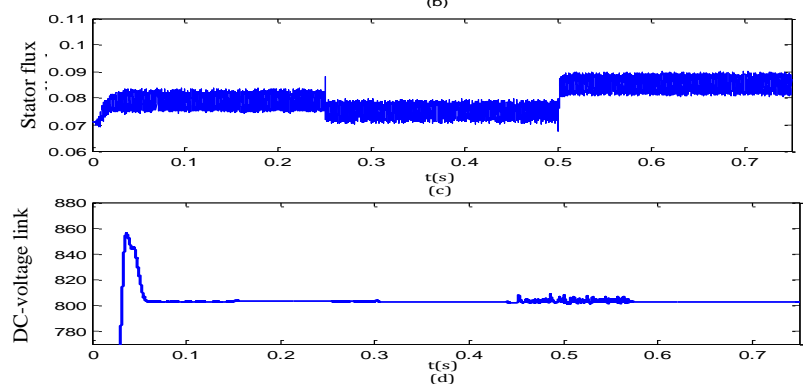

Fig. 8. a) Rotational speed, b) Electromagnetic torque d-axis stator current, c) Stator flux amplitude d) DC-link voltage (SOC=100\%).

\section{B. Test for variable loads demand}

A second test was performed in order to validate the proposed control system under varying loads demand. In this case, the power demand of the DC equivalent load $\left(P_{L d c}\right)$ changes from $5 \mathrm{~kW}$ to $8 \mathrm{~kW}$ at $0.25 \mathrm{~s}$ then increases to $10 \mathrm{~kW}$ at $0.5 \mathrm{~s}$. Further, the unbalanced ohmic-inductive AC load demand $\left(\mathrm{P}_{\mathrm{Lac}}, \mathrm{Q}_{\mathrm{Lac}}\right)$ varies from $(39 \mathrm{~kW}, 0 \mathrm{VAR})$ to $(53 \mathrm{~kW}, 0 \mathrm{VAR})$ at $\mathrm{t}=0.25 \mathrm{~s}$, then changes at $\mathrm{t}=0.5 \mathrm{~s}$ to $(1 \mathrm{~kW}, 15 \mathrm{kVAR})$ and finally varies to $(24 \mathrm{~kW}, 7 \mathrm{kVAR})$ at the instant $\mathrm{t}=0.75 \mathrm{~s}$ as depicted in Fig.9.a and 9.d. As expected the proposed control scheme performs well and reacts dynamically to the change of load conditions without the need to a priori knowledge about the controlled system. The weights of the proposed neuro-controllers are continually adapted during the operation of the system. The decoupled control of the active and reactive powers is achieved based on the recurrent ENNs controllers as shown in Fig9.b and Fig9.d. With reference to the behavior of the proposed fuzzy based PMS, Fig.9.c shows that, the power set- points for the local controllers of both SOFC and BESS are tightly determined according to the availability of the power generated by the RESs. While the RESs with the SOFC stack cannot meet the loads request in the period $[0,0.25 \mathrm{~s}]$, the BESS is activated to feed the energy lack as presented in Fig9.b and Fig9.c. On the contrary, when the power of the MG is not enough in the time interval $[0.25 \mathrm{~s}-0.5 \mathrm{~s}]$, the power deficit is covered by the electric grid, while both FC and BESS are switched on to generate their rated powers as depicted in Fig9.b and Fig9.c. When the total load demand $P_{L}$ does not exceed the available RESs power in the period [0.5s$0.75 \mathrm{~s}]$, the BESS operates in the charge mode and the inverter injects the energy excess into the electric grid. In the period [0.75s-1s], the SOFC stack responds to the load demand where, the BESS is set in the idle mode as shown in Fig9.c. The ADALINE based controllers developed for the SOFC and BESS ensure an accurate following of the references delivered from the PMS as shown in Fig.9.c. The Fig.9.d shows the capability of the inverter to compensate the reactive power of the AC load. To verifiy the performance of the proposed fuzzy PMS, a comparaison with the conventional one based on states is completed. The classical PMS is established based on deterministic supervision rules with the same strategy of power managing of the proposed PMS. The Fig.10 shows the power references for both FC and BESS using the PMS based on states and the supervisory based on FL.

A second case study was performed and depicted in Fig.11, where the DC load demand $\left(P_{L d c}=20 \mathrm{~kW}\right)$ is greater than the AC side demand $\left(P_{L a c}=5 \mathrm{~kW}\right.$ and $\left.Q_{L a c}=O V A R\right)$ and the available RESs power is insufficient $\left(G=0.1 \mathrm{~kW} / \mathrm{m}^{2}, V_{W}=\right.$ $8 \mathrm{~m} / \mathrm{s}$, where initial $S O C=30 \%$ ). In this case, the FEC operates as rectifier and provides the power deficit form the electric grid to the DC load as shown in Fig11.b. The DC link voltage is perfectly maintained in tolerable range as depicted in Fig11.a. It can be noticed that the MPP of PV source is reached using the SN-RBFN after $0.31 \mathrm{~ms}$ as shown in Fig11.b. The obtained results show the ability of the neural based VF-DPC scheme to control the FEC with a bidirectional flow of active power.

\section{Test for Perturbed grid conditions}

This test was performed in order to prove the robustness of the proposed control system against faults in the electric grid. A three-phase voltage sag ( $70 \%$ of voltage RMS) occurs during the period $[0.3 \mathrm{~s}, 0.45 \mathrm{~s}]$ when the climatic conditions are stable. The initial SOC value is set $30 \%$. As shown in Fig12.a, the power needed to feed the loads is provided by the RESs . During the voltage dip period, the active power surplus is injected into the grid. In this case, the central PMS commands are to turn off the SOFC stack and to charge the BESS. Thus, the renewable generation surplus is used to charge the BESS whereas, the FC power is constantly zero as depicted in Fig.12.b. As can be seen from Fig 12.c, the DClink voltage is maintained stable at the desired reference with reduced transient fluctuations. Further, the phase current waveforms shown in Fig.12.d are sinusoidal and balanced irrespective of grid fault. The negative sequences of the inverter output current in the $\alpha \beta$ coordinates, shown in Fig.12.e, demonstrate the symmetry of the FEC output current. 

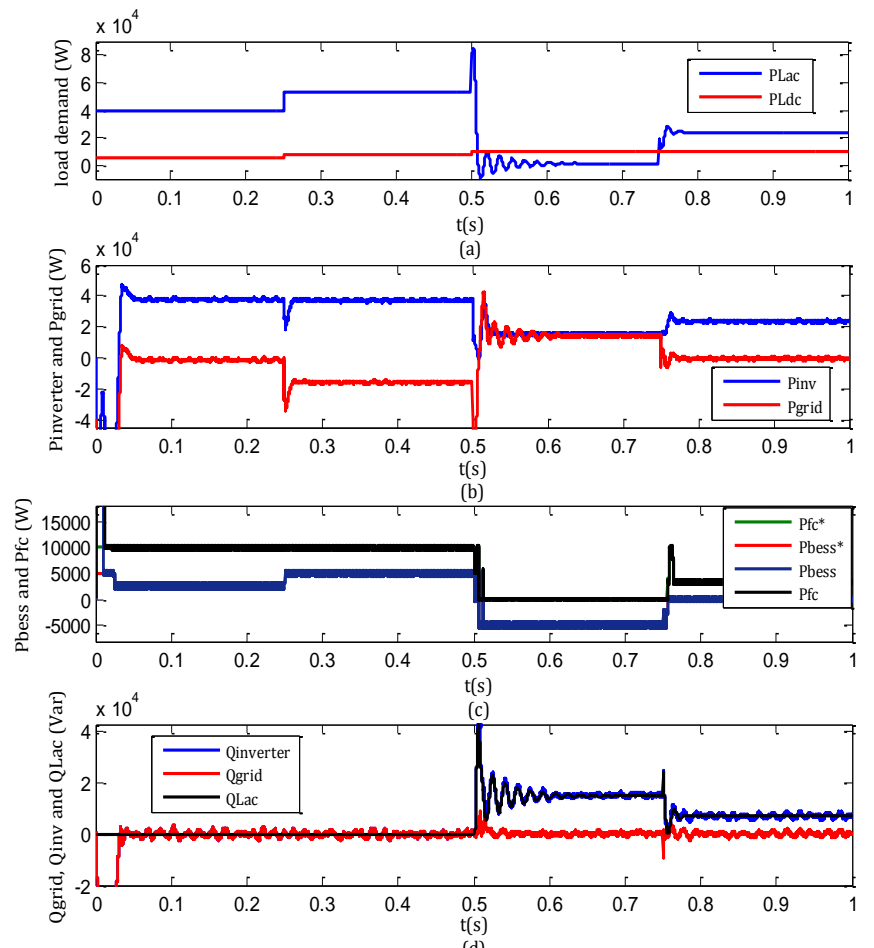

Fig. 9. a) AC and DC loads, b) inverter, and grid Powers c) SOFC and BESS powers d) Inverter, grid and $\mathrm{AC}$ load reactive Powers

$14 \mathrm{~m} / \mathrm{s}, \mathrm{T}=25^{\circ} \mathrm{C}, \mathrm{G}=1 \mathrm{~kW} / \mathrm{m}^{2}$, initial SOC $=70 \%$ ).
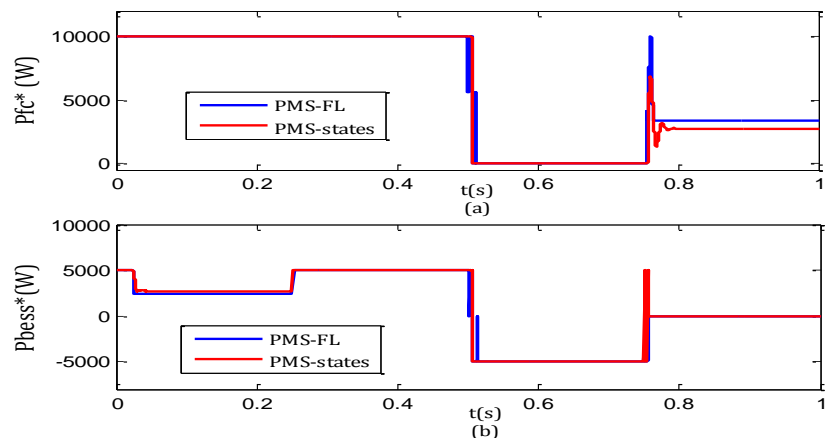

Fig. 10. Comparaison of the PMS based FL and PMS based states.
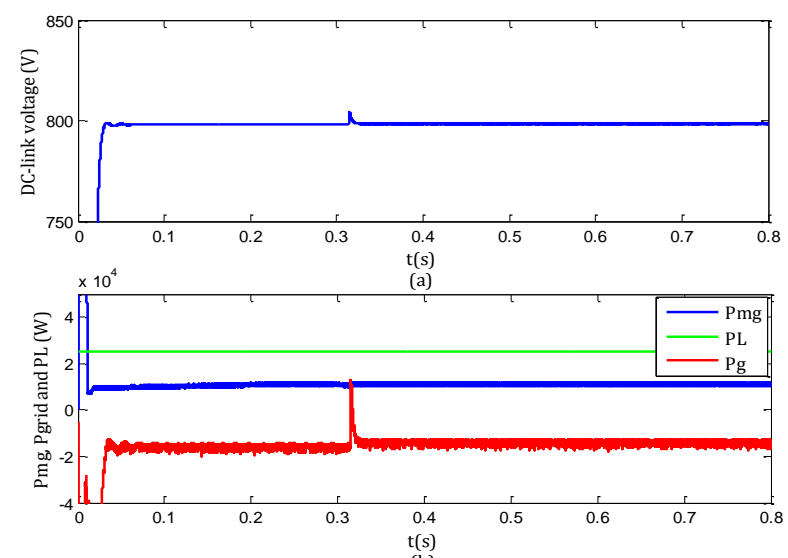

Fig. 11. a) DC bus voltage, b) Total load, microgrid, and grid powers.

\section{Test for variable temperature and noisy wind speed}

This test aims to verify the stability of the proposed control method under changing temperature and noisy wind speed. At constant irradiance $\left(G=1 \mathrm{~kW} / \mathrm{m}^{2}\right.$ and initial $\left.\left.\mathrm{SOC}=90 \%\right)\right)$, the temperature varies at the instant $0.25 \mathrm{~s}$ from $27^{\circ} \mathrm{C}$ to $25^{\circ} \mathrm{C}$ and then decreases at $0.5 \mathrm{~s}$ to $23^{\circ} \mathrm{C}$. The Fig 13.b illustrates the wind speed profile. According to [36], the wind speed is calculated using the following model:

$$
V_{W}=A_{0}+0.6 \sin (\omega t)+0.6 \sin (3.5 \omega t)+0.3 \sin (12.35 \omega t)+
$$

In our case, the average speed $A_{0}=11.5 \mathrm{~m} / \mathrm{s}, \omega=2 \pi / t_{W}$ and $t_{W}=2.5 \mathrm{~s}$. Furthermore, the DC power demand is decreased from $P_{L d c}=9 \mathrm{~kW}$ to $P_{L d c}=4 \mathrm{~kW}$ at the instant $0.5 \mathrm{~s}$. The active and reactive power demand of the ohmic-capacitive AC load are varied, respectively, from $\left(P_{L a c}=26 \mathrm{~kW}, Q_{L a c}=-15 \mathrm{kVAR}\right)$ to $\left(P_{\text {Lac }}=44 \mathrm{~kW}, Q_{\mathrm{Lac}}=-38 \mathrm{kVAR}\right)$ at $\mathrm{t}=0.35 \mathrm{~s}$ then change to the initial values at the instant $0.705 \mathrm{~s}$.
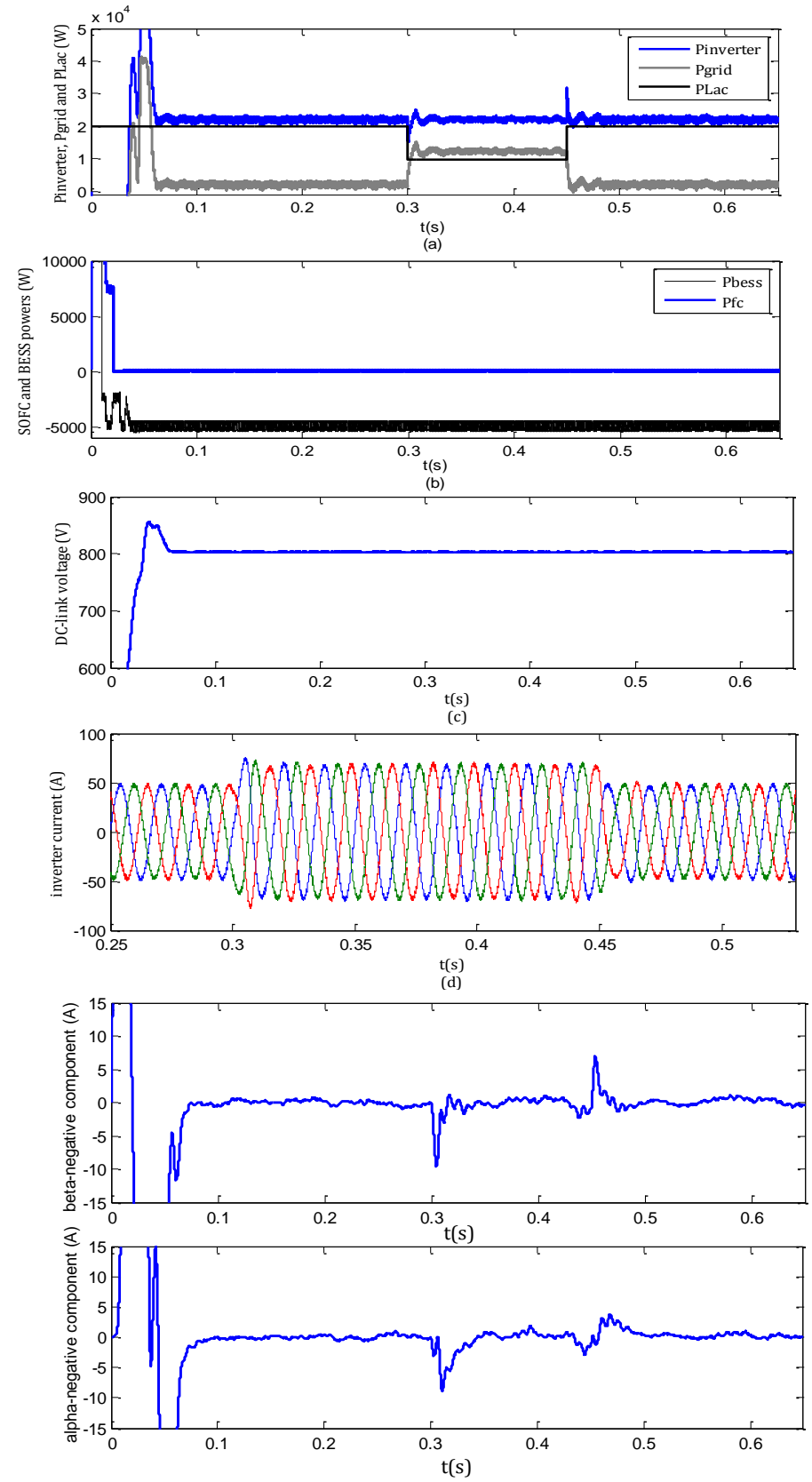

Fig. 12. a) AC load, inverter, and grid powers b) SOFC and BESS powers c)

DC-link voltage d) Inverter output current under voltage sag e) Negative sequences of the inverter current in the $\alpha \beta$ coordinates.

With reference to the Fig.13.a, the proposed SN-RBFN exhibits satisfactory tracking performance and offer a less static PV voltage oscillations than the IncCond algorithm. The 
response time of the SN-RBFN is less (about $35 \mathrm{~ms}$ ) than that of the IncCond controller (70ms). As can be seen from Fig.13.c, the ADALINE based speed controller ensures good control performances for a noisy wind speed
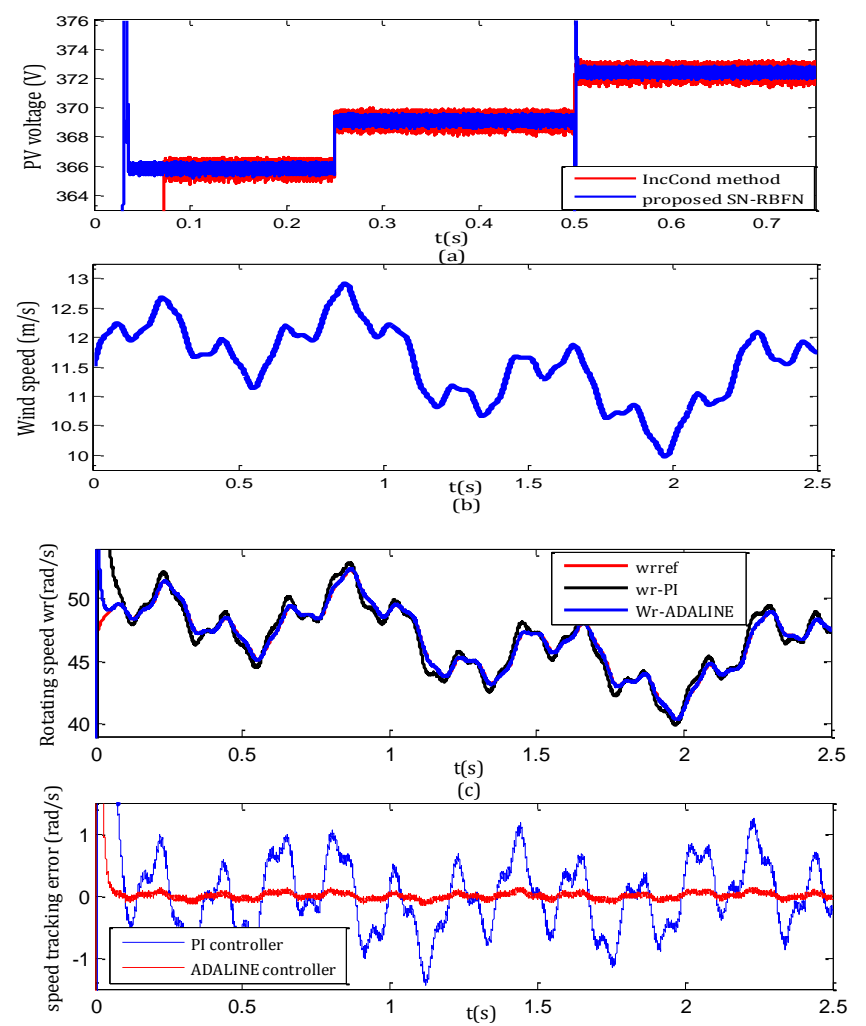

(d)
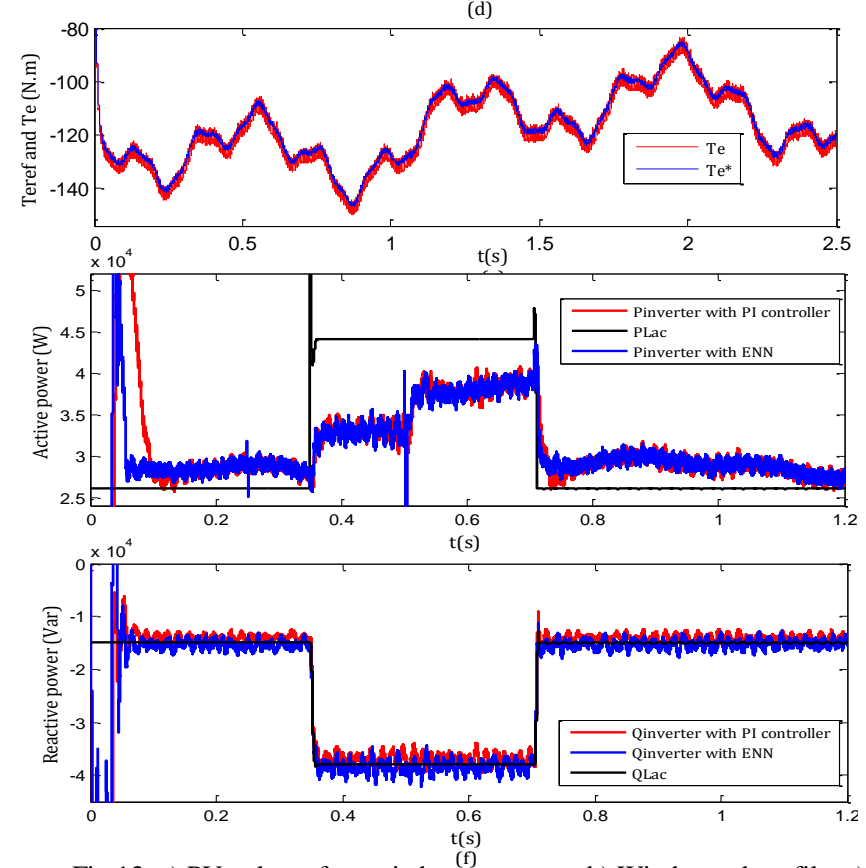

Fig.13. a) PV voltage for varied temperature , b) Wind speed profile, c) rotational speed ,d) speed tracking error, e) generator torque, f) inverter active and reactive powers.

The Fig.13.d shows that the tracking error is considerably reduced in comparaison with the classical PI controller. Moreover, the electromagnetic torque follows perfectly the varied set-point with closely zero static error as depicted in Fig.13.e. Furthermore, the proposed VF-DPC scheme guarantees the response to the AC loads demand of active and reactive power as shown in Fig.13.f with better control performances than the classical VF-DPC based PI regulators: With the ENN based active power control, a shorter settling time and more smooth static response is obtained. Whereas, a more precise tracking of the reactive power setpoint is achieved with the adopted ENN.

\section{CONCLUSION}

This work is on the design and validation of an online trained neural network based control system for a gridconnected hybrid AC/DC microgrid.

A number of artificial intelligence based controllers have been developed to follow the maximum power point of the renewable energy sources available in the microgrid, to control the power flow between the front-end converter and the electric grid, and to minimize the purchased energy optimizing the utilization of the battery energy storage system.

The performance of the proposed control system has been tested for different situations: variable climate conditions, variable loads demand, and perturbed grid conditions.

The obtained results show the possibility to control complex non-linear systems without the availability of precise models. Moreover, the proposed techniques are flexible, adaptable, require low computational costs, and are easy to implement in real-time applications.

The simulation runned for a number of different conditions of power generation and demand demonstrate the effectiveness, robustness and self-adaptation ability of the proposed control system.

As perspective of this paper, the developed artificial intelligence based controllers will be implemented on a Field Programmable Gate Array (FPGA) platform and tested under real conditions.

\section{REFERENCES}

[1] F. Nejabatkhah, Y.W. Li, "Overview of Power Management Strategies of Hybrid AC/DC Microgrid”, IEEE Trans. Power Electronics, Vol 30, no.12,pp.7072-7089, 2015.

[2] M. Mao, P. Jin, N. D. Hatziargyriou, L. Chang, "Multiagent-Based Hybrid Energy Management System for Microgrids," IEEE Trans. Sustainable Energy, Vol. 5, No. 3, pp. 938- 946, July 2014.

[3] A. Milczarek, M. Malinowski, J. M. Guerrero, "Reactive Power Management in Islanded Microgrid-Proportional Power Sharing in Hierarchical Droop Control," IEEE Trans. Smart Grid, Vol. 6, No. 4, pp.1631-1638, July 2015.

[4] K. A. Alobeidli, M. H. Syed, M. S. El Moursi, H. H. Zeineldin, "Novel Coordinated Voltage Control for Hybrid Micro-Grid With Islanding Capability" IEEE Trans. Smart Grid, Vol. 6, No. 3, pp.1116-1127, 2015.

[5] X. Liu, P. Wang, P. C. Loh, "A Hybrid AC/DC Microgrid and Its Coordination Control," IEEE Trans. Smart Grid, vol. 2, no. 2, pp. 278286 , June 2011.

[6] N. Eghtedarpour , E. Farjah, "Power Control and Management in a Hybrid AC/DC Microgrid," IEEE Trans. Smart Grid, vol. 5, no. 3, pp. 1494-1505, May 2014.

[7] M. Hosseinzadeh, F. R.Salmasi, "Robust Optimal Power Management System for a Hybrid AC/DC Micro-Grid,"IEEE Trans. Sustainable Energy, Vol. 6, No. 3, pp.675- 687, July 2015.

[8] Y. Xu, W.Zhang, G. Hug, S. Kar, Z. Li, "Cooperative Control of Distributed Energy Storage Systems in a Microgrid," IEEE Trans. Smart Grid, Vol. 6, No. 1, pp. 238-248, January 2015.

[9] W. Qiao, X. Yang, X. Gong, "Wind Speed and Rotor Position Sensorless Control for Direct-Drive PMG Wind Turbines," IEEE Trans. Ind. Appl., Vol. 48, No. 1, pp.3-11,2012. 
[10] S. Kazemlou, S. Mehraeen, "Decentralized Discrete-Time Adaptive Neural Network Control of Interconnected DC Distribution System," IEEE Trans. Smart Grid, Vol.5, No.5,pp. 2496- 2507, 2014.

[11] W.M. Lin, C.M. Hong, C.H. Chen, "Neural-Network-Based MPPT Control of a Stand-Alone Hybrid Power Generation System," IEEE Trans. Power Electron., Vol. 26, No. 12, pp. 3571-3581, December 2011.

[12] F. Islam, A. Al-Durra, S. M. Muyeen, "Smoothing of Wind Farm Output by Prediction and Supervisory-Control-Unit-Based FESS," IEEE Trans. Sustainable Energy, Vol.4, No.4, pp.925-933, October 2013.

[13] T.O. Kowalska, F. Blaabjerg, J. Rodríguez, "Advanced and Intelligent Control in Power Electronics and Drives," Studies in Computational Intelligence, Vol. 531, Springer Inter.Publishing Switzerland, 2014.

[14] A. Al Nabulsi, R. Dhaouadi, "Efficiency Optimization of a DSP-Based Standalone PV System Using Fuzzy Logic and Dual-MPPT Control," IEEE Trans. Ind. Inf., vol. 8, no.3, pp. 573-584, 2012.

[15] M. Chinchilia, S. Arnaltes, J.Burgos, "Control of permanent-magnet generator applied to variable-speed wind-energy systems connected to the grid", IEEE Trans. Energy Convers., vol 21, no.1, 2006.

[16] B. Wu, Y. Lang, N. Zargari, S. Kouro "Power conversion and control of wind energy systems," John Wiley \& Sons Inc. and IEEE Press; 2011.

[17] A.Y. Sendjaja , V.Kariwala, "Decentralized Control of Solid Oxide Fuel Cells," IEEE Trans. Ind. Inf., Vol. 7, No. 2, pp.163-170, May 2011.

[18] L. Wang, D.J. Lee, "Load-Tracking Performance of an Autonomous SOFC-Based Hybrid Power Generation/Energy Storage System" IEEE Trans. Energy Convers., Vol. 25, No. 1, pp.128-139, March 2010.

[19] O. Tremblay, L.A. Dessaint, A.I.Dekkiche, "A Generic Battery Model for the Dynamic Simulation of Hybrid Electric Vehicles," IEEE Vehicle Power and Propulsion Conference, pp.284 - 289, 2007.

[20] A. Safari , S. Mekhilef, "Simulation and Hardware Implementation of Incremental Conductance MPPT With Direct Control Method Using Cuk Converter", IEEE trans. on ind. Electron., Vol. 58, No. 4,pp. 11541161,April 2011.

[21] B. Subudhi, R.Pradhan, "A Comparative Study on Maximum Power Point Tracking Techniques for Photovoltaic Power Systems," IEEE Trans. Sustainable Energy, Vol. 4, No. 1, pp.89-98, January 2013.

[22] P. K. Dash, S. Mishra, and G. Panda, "A Radial Basis Function Neural Network Controller for UPFC," IEEE Trans. Power Syst., vol. 15, no. 4, November 2000.

[23] A. I. Dounis , P. Kofinas , G. Papadakis , C. Alafodimos "A direct adaptive neural control for maximum power point tracking of photovoltaic system," Solar Energy, vol. 115, pp. 145-165, 2015.

[24] A. Bouafia, J.P. Gaubert, F. Krim, "Predictive Direct Power Control of Three-Phase Pulsewidth Modulation (PWM) Rectifier Using SpaceVector Modulation (SVM), " IEEE Trans. Power Electron., Vol. 25, No. 1, pp.228-236, January 2010.

[25] P. Cortés, M. P. Kazmierkowski, R. M. Kennel,D. E. Quevedo, José Rodríguez, "Predictive Control in Power Electronics and Drives", IEEE Trans. Indus. Electron., Vol. 55, No. 12, pp. 4312-4324, 2008.

[26] N. Li ,Y. Ming, X. Dian-guo, "Predictive Current Control for Permanent Magnet Synchronous Motor Based on deadbeat Control", 7th IEEE Conf. on Industrial Electronics and Applications (ICIEA), 2012.

[27] J. Rodriguez, P. Cortes, "Predictive Control of Power Converters and Electrical Drives", IEEE John Wiley \& Sons, Ltd., Publication. 2012.

[28] D. Ould Abdeslam, P. Wira, D. Flieller, J. Mercklé, "Artificial Neural Networks to Control an Inverter in a Harmonic Distortion Compensation Scheme," in ISIE'2008, Cambridge, UK, 2008, pp.1873-1878, 2008.

[29] D. Biel, F. Guinjoan, E. Fossas, J. Chavarria, "Sliding-Mode Control Design of a Boost-Buck Switching Converter for AC Signal Generation", IEEE Trans. circuits and systems-I, Vol. 51, No. 8, pp. 1539-1551, August 2004.

[30] M. Malinowski, M.P. Kazmierkowski, S. Hansen, F. Blaabjerg, G.D.Marques, "Virtual-Flux-Based Direct Power Control of ThreePhase PWM Rectifiers," IEEE Trans Ind. Appl., Vol.37, no.4, pp. 1019 $-1027,2001$.

[31] R.D. Brandt, F. Lin, "Adaptive interaction and its application to neural networks," Inf. Sci. vol. 121, pp.201-215, 1999.

[32] X. Li, Z.Q. Chen, Z.Z. Yuan, "Generating chaos by an Elman network," IEEE Trans. Circuit Syst. I: Fundam. Theory Appl., Vol. 48, pp.11261131, 2001.

[33] T.C. Ou , C.M. Hong, “ Dynamic operation and control of microgrid hybrid power systems", Energy, Vol.66, pp.314-323, 2014.

[34] N. Siddique, "Intelligent Control: A Hybrid Approach Based on Fuzzy Logic, Neural Networks and Genetic Algorithms", Studies in
Computational Intelligence, Vol.517, Springer Inter. Publishing Switzerland, 2014.

[35] G. Sulligoi, D. Bosich, G. Giadrossi, L. Zhu, M. Cupelli, A. Monti, "Multiconverter Medium Voltage DC Power Systems on Ships: Constant-Power Loads Instability Solution Using Linearization via State Feedback Control," IEEE Trans. Smart Grid, Vol. 5, No. 5, pp.25432552, September 2014.

[36] J. G. de Matos, F.S. F. e Silva, L.A. de S. Ribeiro, "Power Control in AC Isolated Microgrids With Renewable Energy Sources and Energy Storage Systems", IEEE Trans. Indus. Electron.Vol. 62, No.6,pp.34903498, June 2015.

\section{BIOGRAPHIES}

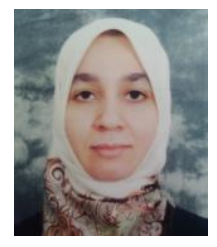

Nadjwa Chettibi received the B.Eng. and the M.Sc. degrees in electronics from the University of Jijel, Jijel, Algeria, in 2008 and 2012, respectively. She is currently working toward the Ph.D. degree in the Department of Electronic at the University of Jijel, Algeria. Her research interests include renewable energy sources, hybrid microgrids, intelligent control and power converters.

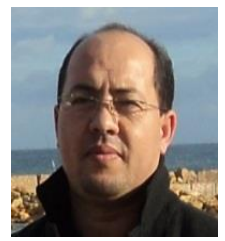

Adel Mellit received the M.Sc.Eng. and Ph.D. degrees, from $\mathrm{HB}$ University of Sciences and Technology (USTHB), Algeria in 2001 and 2006 respectively, both in electronics. He is currently a professor of renewable energy and the head of renewable energy laboratory, at Jijel University, Algeria. His research interests include photovoltaic systems and solar energy materials. Dr. Mellit is an associate member at the ICTP, Trieste Italy.

Giorgio Sulligoi (M'02) received the M.S. degree (with honors) in electrical

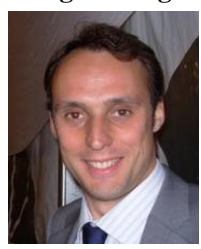
engineering from the University of Trieste, Italy, in 2001, and the Ph.D. degree in electrical engineering from the University of Padua, Italy, in 2005. He spent an internship at Fincantieri Electric Systems Office (Trieste), and a semester as a Visiting Scholar at the University College of Cork (Ireland). In 2005, he joined MAI Control Systems, Milan, Italy, an Italian firm operating in the field of power stations and alternator voltage control systems. Since 2007 he is an Assistant Professor of electric power generation and control in the Department of Engineering and Architecture, University of Trieste (Italy). He is member of PES, where he serves in the MARSYS and GOLD committees.

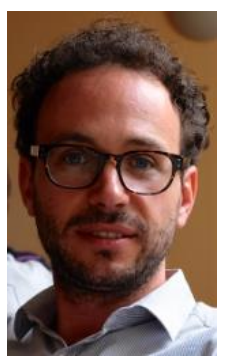

Alessandro Massi Pavan received his master's degree in Electrical Engineering and $\mathrm{PhD}$ in Material Science and Engineering at the University of Trieste in 2002 and 2008, respectively. He is currently Adjunct Professor of photovoltaics at the Department of Engineering and Architecture, University of Trieste, Italy. $\mathrm{He}$ is the Coordinator of the Summer School on Energy "Giacomo Ciamician". He has been a consultant for more than ten years in the power industry. In the photovoltaic sector, his experience as the head of the engineering office in one of the most important worldwide system integrator gave him the expertise developed in two of the largest worldwide photovoltaic markets, Italy and Germany. His current research interests include photovoltaics, renewable energy sources and microgrids. 